\title{
Neural stem cells: mechanisms and modeling
}

\author{
Jun Yao", Yangling Mu* , Fred H. Gage ${ }^{\bowtie}$ \\ Laboratory of Genetics, The Salk Institute for Biological Studies, La Jolla, CA 92037, USA \\ $\square$ Correspondence: gage@salk.edu \\ Received February 21, 2012 Accepted February 21, 2012
}

\begin{abstract}
In the adult brain, neural stem cells have been found in two major niches: the hippocampus and the olfactory bulb. Neurons derived from these stem cells contribute to learning, memory, and the autonomous repair of the brain under pathological conditions. Hence, the physiology of adult neural stem cells has become a significant component of research on synaptic plasticity and neuronal disorders. In addition, the recently developed induced pluripotent stem cell technique provides a powerful tool for researchers engaged in the pathological and pharmacological study of neuronal disorders. In this review, we briefly summarize the research progress in neural stem cells in the adult brain and in the neuropathological application of the induced pluripotent stem cell technique.
\end{abstract}

KEYWORDS neural stem cell, hippocampus, olfactory bulb, induced pluripotent stem cell, neurodegenerative disease, neurodevelopmental disorder

\section{INTRODUCTION}

Since 1965, when newly generated neurons were first discovered in the adult mammalian brain by Altman and Das using $\left[{ }^{3} \mathrm{H}\right]$-thymidine (Altman and Das, 1965), exploration of the precursor cells or stem cells of neurons has been one of the most important tasks for neuroscientists. In the early 1990s, neural stem cells (NSCs) were successfully isolated from mammalian brains (Reynolds and Weiss, 1992). Shortly thereafter, by means of powerful new markers for dividing cells, such as BrdU (Kuhn et al., 1996), NSCs were eventually determined to be largely focused in two regions in the adult brain, the subgranular zone (SGZ) of the dentate gyrus of the hippocampus and the subventricular zone (SVZ) of the

*J.Y. and Y. M. contributed equally to the work. forebrain. All these cells are characterized by the capabilities of self-renewing and producing neurons and glial cells through asymmetric division. Translational research on NSCs isolated from the adult brains or embryos of mammals has become an important topic not only for neuroscientists but also in the medical field, especially in the treatment and modeling of neurodegenerative and neurodevelopmental diseases. A striking breakthrough in NSC research occurred recently when researchers were able to transform skin fibroblasts into induced pluripotent stem cells (iPSCs) and further differentiate them into neurons. The iPSC technique can generate an almost unlimited amount of cultured human neurons, with closely related genomes to those neurons in patients with neuronal disorders from which the fibroblasts were derived and thus provides a powerful means to extensively study the disorders. In this review, we briefly summarize the in vivo differentiation of NSCs in the two neurogenesis niches, the signaling pathways that regulate the differentiation of NSCs, neurogenesis in animal models of neuronal disorders, and the application of NSCs in research on neuronal disorders.

\section{NEUROGENESIS IN THE ADULT MAMMALIAN BRAIN}

In the adult brain, the SGZ of the dentate gyrus and the SVZ of the lateral ventricles (Corotto et al., 1993; Luskin, 1993; Seki and Arai, 1993) are the two major niches of NSCs, although a very small number of stem cells might also exist in other brain regions (Rietze et al., 2000). It is generally accepted that there are two types of NSCs that can be differentiated on the basis of morphology, molecular marker expression and proliferation kinetics (Suh et al., 2009; Mu et al., 2010). In the hippocampal dentate gyrus, type 1 NSCs have been hypothesized to be quiescent stem cells. They usually have a radial process spanning the entire granule cell layer and ramifying in the inner molecular layer, and they can be 
characterized by the expression of specific molecular markers such as GFAP, Sox2 and Nestin. These cells generate non-radial type 2 NSCs that can actively self-amplify and express Sox2 and Nestin, but not GFAP. These intermediate NSCs then give rise to Dcx-positive neuroblasts that differentiate into glutamatergic dentate granule cells (DGCs) (Fig. 1A). Young adult rats generate $\sim 9000$ new cells in the SGZ daily; approximately half of them survive (Cameron and McKay, 2001). The surviving cells develop synaptic connections with the entorhinal cortex and the CA3 subfield, thereby integrating into the existing neuronal circuits (van Praag et al., 2002; Toni et al., 2007).

In the other major niche, the SVZ, a specialized structure in the lateral wall of the lateral ventricles, there are three types of NSCs, which are designated as type A, B and C (Fig. 1B). The type $B$ and $C$ cells correspond to the type 1 and type 2 NSCs in the SGZ, respectively, but in the SVZ there is also a large population of Dcx- and PSA-NCAM-positive neuroblasts that are categorized as type A cells; these only give rise to neurons. In the presence of regulatory growth factors, NSCs in the SVZ can proliferate through symmetric division and generate progenitor cells of neurons through asymmetric division. These progenitor cells migrate from the SVZ to the olfactory bulb through the rostral migratory stream (RMS) (O'Keeffe et al., 2009; Curtis et al., 2011). The RMS in the adult brain is a vestigial lumen that connects the lateral ventricle to the olfactory ventricle. When the neurons reach the olfactory bulb, they are integrated into the granule cell layer and the periglomerular layer to become GABAergic interneurons (Altman, 1969; Lois and Alvarez-Buylla, 1994; Doetsch et al., 1997; Peretto et al., 1997, 1999; Peretto et al., 2005; Ponti et al., 2006; Bonfanti and Peretto, 2007; Bonfanti et al., 2008; Bonfanti and Theodosis, 2009). The size of the
NSC pool in the SVZ is much larger than that in the dentate gyrus (Lois and Alvarez-Buylla, 1993; Morshead et al., 1994). Studies based on animal disease models revealed that neural progenitor cells in the SVZ can also migrate to regions where neuronal disorders occur to compensate for the loss of living neurons (Arvidsson et al., 2002; Tattersfield et al., 2004). Due to the constitutive migration and high proliferation rate of neural progenitor cells in the SVZ (Lucassen et al., 2010; Curtis et al., 2011), it has been proposed that the neuronal differentiation of NSCs in the SVZ might be particularly important for the autonomous repair of the brain during the pathogenesis of a disease.

\section{FACTORS REGULATING NSC DIFFERENTIATION}

Endogenous NSCs can generate neurons, astrocytes, and oligodendrocytes, all of which express their own specific markers, TUJI, GFAP, and GalC, respectively. The different fates of the NSCs are determined by a complex regulatory system composed of a large number of morphogens, growth factors, surrounding cells, and transcription factors, as well as epigenetic mechanisms. Here, we briefly introduce the role of the first four mechanisms in the differentiation and proliferation of NSCs.

Morphogens are a group of proteins that not only are vital for the embryonic development and patterning of the brain but also function to regulate the self-renewal and differentiation of NSCs in the adult brain. This group of proteins includes Notch, sonic hedgehog (Shh), wingless-type MMTV integration site family (Wnt), fibroblast growth factor (FGF), and bone morphogenetic proteins (BMPs). During the process of embryonic development, embryonic stem cells (ESCs) in the ectoderm differentiate into excitatory and inhibitory

(A)

(B)

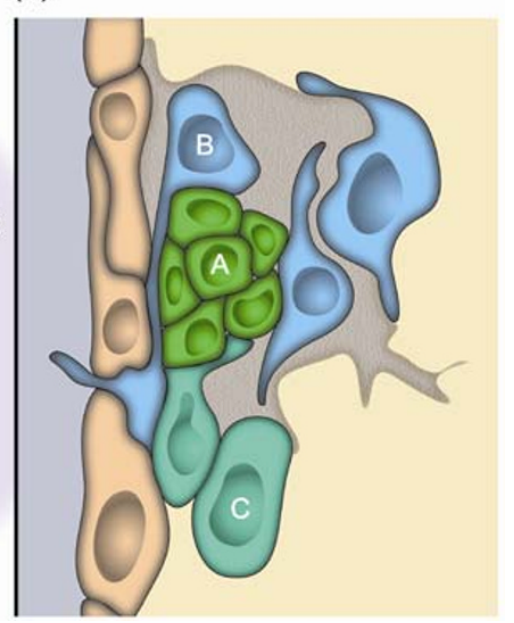

Figure 1. NSCs in the two neurogenic niches of the adult brain (adapted from Zhao et al., 2008 with permission of reprint from the original publisher). (A) In the SGZ of the dentate gyrus, the radial glial-like type 1 progenitor cells, the non-radial type 2 progenitor cells, and neuroblasts that only give rise to neurons are identified. (B) In the olfactory bulb, type B and C cells correspond to the type 1 and 2 progenitor cells in the SGZ, respectively, and type A cells are neuroblasts. DGC, dentate granule cell; GCL, granular cell layer. 
neurons. These morphogenetic proteins, combined at different concentrations, act to pattern the brain along the anterior-posterior and dorsal-ventral axis into different regions. For instance, FGF is responsible for the anterior-posterior patterning and BMP and Shh are specific for the dorsal-ventral patterning; Wnt contributes to both processes. In the adult brain, the morphogenic proteins continue to subtly modulate the number and differentiation of neural precursor cells. In both the SGZ and the SVZ, Shh is essential for the maintenance of radial glia-like cells (Ahn and Joyner, 2005; Balordi and Fishell, 2007; Han et al., 2008), whereas Notch is fundamental for the neuronal differentiation of NSCs (Imayoshi et al., 2010; Pierfelice et al., 2011). Wnt can also promote the neuronal differentiation of NSCs in the SGZ (Lie et al., 2002), whereas BMP determines the glial fate of NSCs (Lim et al., 2000; Bonaguidi et al., 2005; Mira et al., 2010).

The concurrent action of these morphogens via a concentration gradient leads to the differentiated expression of hundreds of transcription factors to determine the fate of newborn neurons. During embryonic development, along the anterior-posterior axis, Otx1 and Foxg1 act as anterior transcription factors and Hox-b4/c5/c8 are posterior transcription factors, whereas along the dorsal-ventral axis, Gsx2 and Nkx2.1 are ventral transcription factors and Pax6 and Tbr1 are dorsal transcription factors (Liu and Zhang, 2011). However, limited information is available on the roles that transcription factors play in NSC differentiation in the adult brain, and only a handful of transcription factors have been extensively studied. One such factor is Sox2, which is present in both the SGZ and SVZ, and colocalizes with NSC markers GFAP, nestin, BLBP, and Musashi-1 (Ferri et al., 2004; Komitova and Eriksson, 2004; Suh et al., 2007; Lugert et al., 2010). Evidence based on transgenic mice revealed that Sox2 acts to regulate the proliferation of NSCs in the SGZ and SVZ (Ferri et al., 2004; Favaro et al., 2009), probably through an interactive regulation with Notch signaling (Taranova et al., 2006; Ehm et al., 2010). Another well-studied transcription factor is Pax6, which is expressed in type 1 NSCs in the SGZ (Maekawa et al., 2005; Nacher et al., 2005; Hodge et al., 2008; Roybon et al., 2009) and in neuroblasts in the SVZ (Herold et al., 2011; Jones and Connor, 2011) and functions to promote the dopaminergic fate determination of NSCs (Kohwi et al., 2005; Brill et al., 2008; Spitere et al., 2008). A third example, Tbr1, is localized in the olfactory bulb and cortex and promotes the neuronal differentiation of NSCs in the SVZ (Hevner et al., 2001; Englund et al., 2005; Méndez-Gómez et al., 2011). Although many other transcription factors (Hodge and Hevner, 2011) have been found to be present in adult NSCs or immature neurons, their exact functions in the maintenance and fate determination of adult NSCs remain elusive.

Abundant evidence support the finding that NSC differentiation in the adult SVZ and SGZ is closely regulated by the local environmental factors, such as glial cells, newborn neurons, and non-neuronal cells (Suh et al., 2009). First of all, the generation of new neurons by NSCs is definitely influenced by the surrounding newly differentiated neurons. Due to the lack of AMPAR-mediated glutamatergic transmission at the early developmental stage, NMDAR has been proposed to be the major type of glutamate receptor that has an effect on the physiology of NSCs (Kitayama et al., 2004; Nácher et al., 2007; Wegner et al., 2009). This hypothesis is also based on the important role of NMDARs in long-term learning and memory. Indeed, in the SGZ, NSC proliferation was found to be inhibited by NMDAR activation in a feedback manner (Cameron et al., 1995), through either the activation of dentate gyrus granule cells or direct NMDAR signaling in the NSCs. Evidence based on cultured NSCs supports the finding that nNOS gene expression is involved in the feedback modulation of NSC differentiation by NMDARs ( $\mathrm{Hu}$ et al., 2008). Interestingly, several other studies using NSC cultures have suggested that NMDA activation could promote the neuronal fate determination of NSCs (Deisseroth et al., 2004; Kitayama et al., 2004; Yoneyama et al., 2008). Hence, the differentiation and proliferation of NSCs is likely subtly regulated by activity within a range; too-high or too-low levels of neuronal activity can both delay the process of neurogenesis.

Another type of neurotransmission that may significantly affect NSCs is GABAergic transmission, not only because of its very early appearance but also due to its specific excitatory characteristics in NSCs and immature neurons (MuthKöhne et al., 2010; Cherubini et al., 2011). Unlike its inhibitory effects in mature neurons, the release of GABA triggers an efflux of $\mathrm{Cl}^{-}$in NSCs and new neurons, leading to depolarizing inward currents. The efflux of $\mathrm{Cl}^{-}$in these cells is due to the reversed $\mathrm{Cl}^{-}$concentration gradient across the plasma membrane, which is determined by the expression of NKCC1, an ion cotransporter. Functionally, the GABA-induced excitatory transmission acts as a developmental compensation for the largely absent glutamatergic transmission, especially AMPAR-mediated responses, in young neurons. GABAR activation promotes neuronal differentiation in the SGZ and neuroblast migration in the SVZ (Tozuka et al., 2005; Ge et al., 2006; Mejia-Gervacio et al., 2011). On the other hand, in the SVZ, the GABAergic transmission can delay the proliferation of NSCs (Liu et al., 2005). Although the relevant mechanisms have remained elusive, they probably involve activity-dependent modulation and might be related to the activation of NMDARs.

Furthermore, astrocytes can promote the differentiation of NSCs into neurons and the development of immature neurons (Lim and Alvarez-Buylla, 1999; Song et al., 2002a, 2002b; Yuan et al., 2012), probably through the secretion of Wnt3, a neurogenic factor (Muroyama et al., 2004; Lie et al., 2005; Yoshinaga et al., 2010). Notably, this Wnt3-secreting function of astrocytes is only limited to the cells in the hippocampus but not from other areas. Interestingly, as neurons appear prior to astrocytes during the process of development, 
astrocytes might specifically regulate the differentiation of NSCs in the developed brain. Given these two unique physiological features, astrocytes might be particularly important for shaping the dentate gyrus of the hippocampus as a source of neurogenesis in the mature central nervous system.

In addition, NSCs are physically associated with endothelial cells, which allow the diffusion of signaling molecules such as the vascular endothelial growth factor (VEGF) and nutrients from the latter into the former. The promoting effects of VEGF on angiogenesis, neurogenesis, and memory have been confirmed, both in vivo and in vitro (Jin et al., 2002; Cao et al., 2004; Fournier and Duman, 2011; Licht et al., 2011). In addition, the ependymal cells in the SVZ can promote the neuronal differentiation of NSCs by secreting Noggin and the self-renewal of NSCs by secreting the pigment epithelium-derived factor (PEDF) (Jin et al., 2003; Ramírez-Castillejo et al., 2006).

\section{NEUROGENESIS UNDER PATHOLOGICAL CONDITIONS}

The differentiation of NSCs in the SVZ and SGZ has been confirmed to alter under pathological conditions, such as Alzheimer's disease (AD), Parkinson's disease (PD), Huntington's disease (HD), epilepsy, and stroke. Both epilepsy and stroke can promote the differentiation of NSCs in the SGZ and SVZ and the integration of newborn neurons into the neural network (Jessberger et al., 2007; Parent et al., 2007; Walter et al., 2007). Mouse models of both PD and HD have indicated that the pathogenesis of these two diseases can reduce the proliferation of NSCs and the survival of newborn neurons (see review in Winner et al., 2011). Here, we summarize the influence of AD on the activity of NSCs, because considerable evidence has suggested that NSC differentiation is particularly complicated in $A D$, and a variety of key molecules involved in AD can not only negatively but also positively modulate the differentiation of NSCs.

$A D$ pathogenesis has been hypothesized to be triggered by amyloid peptides $(A \beta)$ (Hardy and Selkoe, 2002), which are the cleavage products of the large membrane-integrated amyloid precursor protein (APP) by $\beta$ - and $\gamma$-secretase actions (Selkoe, 2001). Mutations in presenilins (including PS1 and PS2), the catalytic core of $\gamma$-secretase, and APP represent the most important genetic risk factor for the rare, familial, and early-onset autosomal dominant forms of AD (Hardy and Selkoe, 2002). A recent study showed that PS1 deficiency induced a dramatically enhanced differentiation of neural progenitor cells, possibly in a Y-secretase-dependent way (Gadadhar et al., 2011). Expression of a human PS1 mutant (P117L) in transgenic mice decreased the survival of new neurons during the 4-week postlabeling period (Wen et al., 2004). The enriched environment (EE)-induced proliferation and neuronal differentiation of hippocampal progenitor cells in mice harboring the FAD-linked human PS1 variant transgenes (PS1 $\mathrm{E} 9$ or PS1M146L) was significantly impaired, which appeared to involve soluble factors released from microglia (Choi et al., 2008). Similarly, the proliferation and survival of neural progenitor cells were reduced in transgenic mice expressing a mutated form of APP (APPswe) that causes early-onset FAD (Haughey et al., 2002). An agedependent decrease in SGZ proliferation was also observed in mice transgenic for human V717F mutant APP, a model of $A D$ with age-dependent accumulation of A 442 -containing plaques (Donovan et al., 2006). Impaired neuronal differentiation of NPCs was also confirmed in transgenic mice coexpressing two or three mutated genes of APP and PS1 (Verret et al., 2007; Zhang et al., 2007; Rodríguez et al., 2008; Demars et al., 2010). Nevertheless, conflicting observations have been obtained from PDGF-APPswe,ind mice (J20), which express the Swedish and Indiana APP mutations of APP. They showed increased incorporation of BrdU and expression of immature neuronal markers in the dentate gyrus (Jin et al., 2004). A separate study revealed an increase in not only NSC proliferation but also neuronal differentiation in $\mathrm{J} 20$ mice, which were induced by oligomeric $A \beta$ (López-Toledano and Shelanski, 2007). Interestingly, PS1/PS2 conditional double knockout was found to cause neurodegenerative stage-dependent dynamic changes. Cell proliferation was significantly enhanced at the early stages of neurodegeneration, whereas the survival of newly generated neurons was impaired during the late stages (Chen et al., 2008).

\section{MODELING OF NEURONAL DISORDERS WITH NSCS}

In addition to their contribution to the study of the mechanisms of neuronal disorders, an important aspect of NSC research lies in its application in the modeling and treatment (e.g. transplantation, drug screening) of these diseases (Fig. 2).

Cultured neurons derived from human ESCs (hESCs) through co-culture systems (Kawasaki et al., 2000; Roy et al., 2006) or direct differentiation protocols (Chambers et al., 2009) have been used to transplant into animal models to treat neuronal disorders such as PD. Although the new neurons could be functionally integrated, the limited source of host-friendly NSCs has been a major concern. Disease modeling based on ESC culture is also limited for the same reason (Yamashita et al., 2006; Schneider et al., 2007; Crews et al., 2008). Strikingly, since Yamanaka's and Thomson's exciting experiments on iPSCs in 2007 (Takahashi et al., 2007; Yu et al., 2007), the successful reprogramming of fibroblasts has been accomplished for a variety of neurodegenerative and neurodevelopmental diseases, such as amyotrophic lateral sclerosis (ALS), PD (Dimos et al., 2008; Park et al., 2008; Soldner et al., 2009), spinal muscular atrophy (SMA), familial dysautonomia (FD) (Ebert et al., 2009; 


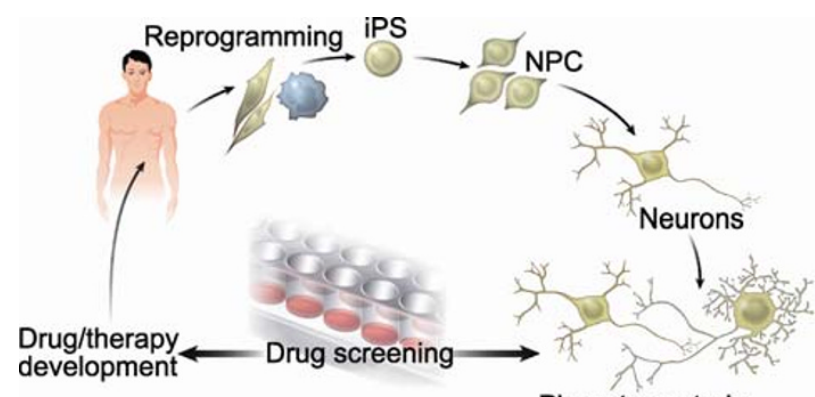

Phenotype study

Figure 2. Modeling of neurodegenerative and neurodevelopmental diseases based on the IPSC technique (adapted from Marchetto et al., 2010b with permission of reprint from the original publisher). Fibroblasts of neurologic patients are reprogrammed and further differentiated into subtypes of neurons. The phenotypes of the neurons, such as morphology, connectivity, and synaptic transmission, are studied to facilitate understanding of the pathology of the diseases and screening drugs or compounds. Drugs and compounds that specifically alleviate or even reverse the pathological phenotypes of the diseases can be further tested to develop optimized therapies.

Lee et al., 2009), and AD (Israel et al., 2012). The reprogramming of patient fibroblasts to human iPSCs, followed by iPSC differentiation into neurons, produces a near limitless source of live human neurons that are genetically identical to those present in patients, with which the disorder can be extensively studied.

SMA is the first neuronal disease that was modeled using the iPSC technique (Ebert et al., 2009). SMA is an autosomal recessive disease that shows either deletions or point mutations in the survival motor neuron (SMN) gene in spinal cord motor neurons. The SMN gene encodes a $20 \mathrm{~kb}$ survival motor neuron protein that plays a role in RNA processing (Bü rglen et al., 1996; Lorson and Androphy, 1998; Lorson et al., $1998,1999)$, and mutations in the SMA protein usually lead to rapid degeneration of motor neurons. FD, which is also an autosomal recessive disease and causes degeneration of sensory and autonomic neurons, not only has been successfully modeled but is also the first neuronal disease that was used for iPSC-based drug screening (Slaugenhaupt et al., 2001; Lee et al., 2009).

A hallmark application of the iPSC technique in neurodegenerative disease research is $P D$, because $P D$ was the first neuronal disorder to be treated by the transplantation of iPSC-derived neurons. PD is the second most common neurodegenerative disease and is characterized by motor symptoms including bradykinesia, tremor, rigidity and postural instability, as well as some non-motor-related symptoms such as sensory dysfunction and sleep disorders. The pathogenesis of PD is caused by the accumulation of misfolded alpha-synuclein into the intracellular Lewy bodies
(Aarsland et al., 2009; Schulz-Schaeffer, 2010; Vekrellis et al., 2011) and insufficient dopamine expression in neurons in the substantia nigra of the midbrain (Goedert, 2001; Braak et al., 2007). Fibroblasts from PD patients have been successfully reprogrammed and differentiated into dopamine neurons (Park et al., 2008; Soldner et al., 2009). Strikingly, Wernig et al. (2008) demonstrated that transplantation of mouse iPSC-differentiated dopamine neurons could be functionally integrated into the midbrain of PD rats. This study represented the first time that researchers attempted to treat a neuronal disorder by grafting iPSC-derived neurons.

Compared to the neurodegenerative diseases mentioned above, the genetic background of neurodevelopmental disorders is usually more complex, making these disorders difficult to study through animal models. Hence, iPSC technology is particularly advantageous in modeling developmentally related neuronal disorders. The first such disease to be modeled was Rett syndrome, which is considered one of the autism spectrum disorders and only affects females. Although Rett syndrome is still a monogenetic disease and its clinical symptoms have been well recapitulated in mouse models, the modeling of Rett syndrome with iPSCs provides a compelling precedent for this type of research. Rett syndrome is characterized by decelerated childhood development, and its clinical symptoms include regression of acquired skills, loss of speech, stereotypical movements, microcephaly, seizures, autistic characteristics and mental retardation (Segawa, 2001; Samaco et al., 2005). Rett syndrome results from mutations in the X-chromosome-linked MeCP2 gene, which regulates gene expression through modulating DNA methylation (Akbarian, 2003; Chahrour and Zoghbi, 2007). Fibroblasts of patients with Rett syndrome have been successfully reprogrammed into iPSCs (Hotta et al., 2009; Marchetto et al., 2010a). In Marchetto et al.'s study, the phenotypes of Rett syndrome were recapitulated in neurons differentiated from patient-derived iPSCs, and have subsequently been extensively studied.

Schizophrenia (SCZD), a neurological disorder characterized by mental and emotional abnormalities, is the first polygenic neurodevelopmental disorder modeled by the iPSC technique (Brennand et al., 2011). Genome-wide association studies (GWAS) have identified a number of genes involved in SCZD. The expression and functions of three major genes, the Disrupted-in-Schizophrenia-1 (DISC1) gene (Kang et al., 2011; Singh et al., 2011; Soares et al., 2011), the Neuregulin-1 (NRG1) gene and its receptor ErbB4 (Pan et al., 2011; Yokley et al., 2011), have been firmly verified to alter during SCZD. Other genes, including transcription factor 4 (TCF4), zinc finger protein 804A (ZNF804A), neurogranin (NRGN), and microRNA 137 (MIR137) (O'Donovan et al., 2008; Stefansson et al., 2009; Ripke et al., 2011) probably contribute to SCZD. In addition to these single genes, chromosomal changes such as the major histocompatibility complex $(\mathrm{MHC})$ region, which contains a couple hundred genes, 
and CNVs, were reported to be related to SCZD (Lee et al., 2012). Due to its complex genetic background, SCZD has a widely differentiated range of symptoms, which can be divided into three major classes: (1) positive symptoms, such as hallucinations and delusions; (2) negative symptoms, such as inability to speak, express emotion, or find pleasure; and (3) cognitive symptoms, such as deficits in attention, memory, and planning (Carpenter and Buchanan, 1994). The molecular and cellular mechanisms underlying the pathogenesis of SCZD remain unknown, largely because animal models are limited for the study of SCZD. Strikingly, fibroblasts of SCZD patients carrying mutations in DISC1 or other relevant genes have been recently successfully reprogrammed into iPSCs (Brennand et al., 2011; Chiang et al., 2011; Pedrosa et al., 2011). Brennand et al. succeeded in recapitulating the phenotypes of SCZD, which were previously revealed by animal studies, in neurons derived from SCZD iPSCs, thus providing a shining example for the iPSC study of polygenic diseases.

\section{CONCLUDING REMARKS}

NSCs are a class of cells that can proliferate to self-renew through symmetric division and differentiate into neurons and glial cells through asymmetric division. In the adult brain, there are two NSC niches, the SGZ of the dentate gyrus and the SVZ of the olfactory bulb. In both niches, three types of precursor cells of neurons have been found, the radial-like and non-radial NSCs and neuroblasts. The NSCs in the SGZ eventually differentiate into glutamatergic granule neurons in the dentate gyrus, while the NSCs in the SVZ produce GABAergic interneurons that are integrated into the neural network in the olfactory bulb. The proliferation and differentiation of NSCs are strictly regulated by a variety of intrinsic and extrinsic mechanisms. Morphogenic proteins and transcription factors are the fundamental forces that determine the fate of NSCs and the process of neurogenesis. The surrounding neurons, astrocytes, and other non-neuronal cells can affect the fate determination and proliferation of NSCs, either in an activity relevant manner or through growth factor release. Abnormalities in adult neurogenesis are often involved in neurodegenerative and neurodevelopmental diseases such as $A D, P D$, and $H D$. Hence, transplantation of neurons derived from cultured NSCs has been employed for the treatment of neural diseases. In addition, NSCs of patients can be used to study the mechanisms underlying the pathogenesis of the neuronal disorders and to test the efficacy and side effects of drugs. Importantly, patient-derived iPSCs provide an almost unlimited source of disease-carrying human neurons and thus are a powerful tool for research on neuronal disorders.

\section{ACKNOWLEDGEMENTS}

We are all grateful to Mary Lynn Gage for helpful comments and editorial support. J.Y. is supported by an American Heart Association postdoctoral fellowship (11POST5720016).

\section{ABBREVIATIONS}

$A \beta$, amyloid peptides; AD, Alzheimer's disease; ALS, amyotrophic lateral sclerosis; APP, amyloid precursor protein; BMPs, bone morphogenetic proteins; DGCs, dentate granule cells; DISC1, Disrupted-in-Schizophrenia-1; ESCs, embryonic stem cells; FD, familial dysautonomia; FGF, fibroblast growth factor; GWAS, genome-wide association studies; hESCs, human ESCs; HD, Huntington's disease; iPSCs, induced pluoripotent stem cells; MHC, major histocompatibility complex; NSCs, neural stem cells; RMS, rostral migratory stream; Shh, sonic hedgehog; PD, Parkinson's disease; PEDF, pigment epithelium-derived factor; SCZD, Schizophrenia; SGZ, subgranular zone; SMA, spinal muscular atrophy; SMN, survival motor neuron; SVZ, subventricular zone; TCF4, transcription factor 4; Wnt, wingless-type MMTV integration site family

\section{REFERENCES}

Aarsland, D., Londos, E., and Ballard, C. (2009). Parkinson's disease dementia and dementia with Lewy bodies: different aspects of one entity. Int Psychogeriatr 21, 216-219.

Ahn, S., and Joyner, A.L. (2005). In vivo analysis of quiescent adult neural stem cells responding to Sonic hedgehog. Nature 437, 894-897.

Akbarian, S. (2003). The neurobiology of Rett syndrome. Neuroscientist 9, 57-63.

Altman, J. (1969). Autoradiographic and histological studies of postnatal neurogenesis. IV. Cell proliferation and migration in the anterior forebrain, with special reference to persisting neurogenesis in the olfactory bulb. J Comp Neurol 137, 433-457.

Altman, J., and Das, G.D. (1965). Autoradiographic and histological evidence of postnatal hippocampal neurogenesis in rats. J Comp Neurol 124, 319-335.

Arvidsson, A., Collin, T., Kirik, D., Kokaia, Z., and Lindvall, O. (2002). Neuronal replacement from endogenous precursors in the adult brain after stroke. Nat Med 8, 963-970.

Balordi, F., and Fishell, G. (2007). Hedgehog signaling in the subventricular zone is required for both the maintenance of stem cells and the migration of newborn neurons. J Neurosci 27, 5936-5947.

Bonaguidi, M.A., McGuire, T., Hu, M., Kan, L., Samanta, J., and Kessler, J.A. (2005). LIF and BMP signaling generate separate and discrete types of GFAP-expressing cells. Development 132, 5503-5514.

Bonfanti, L., Aimar, P., Ponti, G., and Canalia, N. (2008). Immunoelectromicroscopic approach for the study of neural stem cell niches. Vet Res Commun 32, S107-S109.

Bonfanti, L., and Peretto, P. (2007). Radial glial origin of the adult neural stem cells in the subventricular zone. Prog Neurobiol 83, 24-36.

Bonfanti, L., and Theodosis, D.T. (2009). Polysialic acid and activ- 
ity-dependent synapse remodeling. Cell Adh Migr 3, 43-50.

Braak, H., Sastre, M., and Del Tredici, K. (2007). Development of alpha-synuclein immunoreactive astrocytes in the forebrain parallels stages of intraneuronal pathology in sporadic Parkinson's disease. Acta Neuropathol 114, 231-241.

Brennand, K.J., Simone, A., Jou, J., Gelboin-Burkhart, C., Tran, N., Sangar, S., Li, Y., Mu, Y., Chen, G., Yu, D., et al. (2011). Modelling schizophrenia using human induced pluripotent stem cells. Nature 473, 221-225.

Brill, M.S., Snapyan, M., Wohlfrom, H., Ninkovic, J., Jawerka, M., Mastick, G.S., Ashery-Padan, R., Saghatelyan, A., Berninger, B., and Götz, M. (2008). A dlx2- and pax6-dependent transcriptional code for periglomerular neuron specification in the adult olfactory bulb. J Neurosci 28, 6439-6452.

Bürglen, L., Lefebvre, S., Clermont, O., Burlet, P., Viollet, L., Cruaud, C., Munnich, A., and Melki, J. (1996). Structure and organization of the human survival motor neurone (SMN) gene. Genomics 32, 479-482.

Cameron, H.A., McEwen, B.S., and Gould, E. (1995). Regulation of adult neurogenesis by excitatory input and NMDA receptor activation in the dentate gyrus. J Neurosci 15, 4687-4692.

Cameron, H.A., and McKay, R.D. (2001). Adult neurogenesis produces a large pool of new granule cells in the dentate gyrus. $J$ Comp Neurol 435, 406-417.

Cao, L., Jiao, X., Zuzga, D.S., Liu, Y., Fong, D.M., Young, D., and During, M.J. (2004). VEGF links hippocampal activity with neurogenesis, learning and memory. Nat Genet 36, 827-835.

Carpenter, W.T. Jr, and Buchanan, R.W. (1994). Schizophrenia. N Engl J Med 330, 681-690.

Chahrour, M., and Zoghbi, H.Y. (2007). The story of Rett syndrome: from clinic to neurobiology. Neuron 56, 422-437.

Chambers, S.M., Fasano, C.A., Papapetrou, E.P., Tomishima, M., Sadelain, M., and Studer, L. (2009). Highly efficient neural conversion of human ES and iPS cells by dual inhibition of SMAD signaling. Nat Biotechnol 27, 275-280.

Chen, Q., Nakajima, A., Choi, S.H., Xiong, X., Sisodia, S.S., and Tang, Y.P. (2008). Adult neurogenesis is functionally associated with AD-like neurodegeneration. Neurobiol Dis 29, 316-326.

Cherubini, E., Griguoli, M., Safiulina, V., and Lagostena, L. (2011). The depolarizing action of GABA controls early network activity in the developing hippocampus. Mol Neurobiol 43, 97-106.

Chiang, C.H., Su, Y., Wen, Z., Yoritomo, N., Ross, C.A., Margolis, R.L., Song, H., and Ming, G.L. (2011). Integration-free induced pluripotent stem cells derived from schizophrenia patients with a DISC1 mutation. Mol Psychiatry 16, 358-360.

Choi, S.H., Veeraraghavalu, K., Lazarov, O., Marler, S., Ransohoff, R.M., Ramirez, J.M., and Sisodia, S.S. (2008). Non-cell-autonomous effects of presenilin 1 variants on enrichment-mediated hippocampal progenitor cell proliferation and differentiation. Neuron 59, 568-580.

Corotto, F.S., Henegar, J.A., and Maruniak, J.A. (1993). Neurogenesis persists in the subependymal layer of the adult mouse brain. Neurosci Lett 149, 111-114.

Crews, L., Mizuno, H., Desplats, P., Rockenstein, E., Adame, A.,
Patrick, C., Winner, B., Winkler, J., and Masliah, E. (2008). Alpha-synuclein alters Notch-1 expression and neurogenesis in mouse embryonic stem cells and in the hippocampus of transgenic mice. J Neurosci 28, 4250-4260.

Curtis, M.A., Kam, M., and Faull, R.L. (2011). Neurogenesis in humans. Eur J Neurosci 33, 1170-1174.

Deisseroth, K., Singla, S., Toda, H., Monje, M., Palmer, T.D., and Malenka, R.C. (2004). Excitation-neurogenesis coupling in adult neural stem/progenitor cells. Neuron 42, 535-552.

Demars, M., Hu, Y.S., Gadadhar, A., and Lazarov, O. (2010). Impaired neurogenesis is an early event in the etiology of familial Alzheimer's disease in transgenic mice. J Neurosci Res 88, 2103-2117.

Dimos, J.T., Rodolfa, K.T., Niakan, K.K., Weisenthal, L.M., Mitsumoto, H., Chung, W., Croft, G.F., Saphier, G., Leibel, R., Goland, R., et al. (2008). Induced pluripotent stem cells generated from patients with ALS can be differentiated into motor neurons. Science 321 , 1218-1221.

Doetsch, F., García-Verdugo, J.M., and Alvarez-Buylla, A. (1997). Cellular composition and three-dimensional organization of the subventricular germinal zone in the adult mammalian brain. $\mathrm{J}$ Neurosci 17, 5046-5061.

Donovan, M.H., Yazdani, U., Norris, R.D., Games, D., German, D.C., and Eisch, A.J. (2006). Decreased adult hippocampal neurogenesis in the PDAPP mouse model of Alzheimer's disease. J Comp Neurol 495, 70-83.

Ebert, A.D., Yu, J., Rose, F.F. Jr, Mattis, V.B., Lorson, C.L., Thomson, J.A., and Svendsen, C.N. (2009). Induced pluripotent stem cells from a spinal muscular atrophy patient. Nature 457, 277-280.

Ehm, O., Göritz, C., Covic, M., Schäffner, I., Schwarz, T.J., Karaca, E., Kempkes, B., Kremmer, E., Pfrieger, F.W., Espinosa, L., et al. (2010). RBPJkappa-dependent signaling is essential for long-term maintenance of neural stem cells in the adult hippocampus. $J$ Neurosci 30, 13794-13807.

Englund, C., Fink, A., Lau, C., Pham, D., Daza, R.A., Bulfone, A., Kowalczyk, T., and Hevner, R.F. (2005). Pax6, Tbr2, and Tbr1 are expressed sequentially by radial glia, intermediate progenitor cells, and postmitotic neurons in developing neocortex. J Neurosci 25, 247-251.

Favaro, R., Valotta, M., Ferri, A.L., Latorre, E., Mariani, J., Giachino, C., Lancini, C., Tosetti, V., Ottolenghi, S., Taylor, V., et al. (2009). Hippocampal development and neural stem cell maintenance require Sox2-dependent regulation of Shh. Nat Neurosci 12, 1248-1256.

Ferri, A.L., Cavallaro, M., Braida, D., Di Cristofano, A., Canta, A., Vezzani, A., Ottolenghi, S., Pandolfi, P.P., Sala, M., DeBiasi, S., et al. (2004). Sox2 deficiency causes neurodegeneration and impaired neurogenesis in the adult mouse brain. Development 131, 3805-3819.

Fournier, N.M., and Duman, R.S. (2012). Role of vascular endothelial growth factor in adult hippocampal neurogenesis: Implications for the pathophysiology and treatment of depression. Behav Brain Res 227, 440-449.

Gadadhar, A., Marr, R., and Lazarov, O. (2011). Presenilin-1 regu- 
lates neural progenitor cell differentiation in the adult brain. $\mathrm{J}$ Neurosci 31, 2615-2623.

Ge, S., Goh, E.L., Sailor, K.A., Kitabatake, Y., Ming, G.L., and Song, H. (2006). GABA regulates synaptic integration of newly generated neurons in the adult brain. Nature 439, 589-593.

Goedert, M. (2001). Alpha-synuclein and neurodegenerative diseases. Nat Rev Neurosci 2, 492-501.

Han, Y.G., Spassky, N., Romaguera-Ros, M., Garcia-Verdugo, J.M., Aguilar, A., Schneider-Maunoury, S., and Alvarez-Buylla, A. (2008). Hedgehog signaling and primary cilia are required for the formation of adult neural stem cells. Nat Neurosci 11, 277-284.

Hardy, J., and Selkoe, D.J. (2002). The amyloid hypothesis of Alzheimer's disease: progress and problems on the road to therapeutics. Science 297, 353-356.

Haughey, N.J., Nath, A., Chan, S.L., Borchard, A.C., Rao, M.S., and Mattson, M.P. (2002). Disruption of neurogenesis by amyloid beta-peptide, and perturbed neural progenitor cell homeostasis, in models of Alzheimer's disease. J Neurochem 83, 1509-1524.

Herold, S., Jagasia, R., Merz, K., Wassmer, K., and Lie, D.C. (2011). CREB signalling regulates early survival, neuronal gene expression and morphological development in adult subventricular zone neurogenesis. Mol Cell Neurosci 46, 79-88.

Hevner, R.F., Shi, L., Justice, N., Hsueh, Y., Sheng, M., Smiga, S., Bulfone, A., Goffinet, A.M., Campagnoni, A.T., and Rubenstein, J.L. (2001). Tbr1 regulates differentiation of the preplate and layer 6. Neuron 29, 353-366.

Hodge, R.D., and Hevner, R.F. (2011). Expression and actions of transcription factors in adult hippocampal neurogenesis. Dev Neurobiol 71, 680-689.

Hodge, R.D., Kowalczyk, T.D., Wolf, S.A., Encinas, J.M., Rippey, C., Enikolopov, G., Kempermann, G., and Hevner, R.F. (2008). Intermediate progenitors in adult hippocampal neurogenesis: Tbr2 expression and coordinate regulation of neuronal output. J Neurosci 28, 3707-3717.

Hotta, A., Cheung, A.Y., Farra, N., Vijayaragavan, K., Séguin, C.A., Draper, J.S., Pasceri, P., Maksakova, I.A., Mager, D.L., Rossant, J., et al. (2009). Isolation of human iPS cells using EOS lentiviral vectors to select for pluripotency. Nat Methods 6, 370-376.

Hu, M., Sun, Y.J., Zhou, Q.G., Chen, L., Hu, Y., Luo, C.X., Wu, J.Y., Xu, J.S., Li, L.X., and Zhu, D.Y. (2008). Negative regulation of neurogenesis and spatial memory by NR2B-containing NMDA receptors. J Neurochem 106, 1900-1913.

Imayoshi, I., Sakamoto, M., Yamaguchi, M., Mori, K., and Kageyama, R. (2010). Essential roles of Notch signaling in maintenance of neural stem cells in developing and adult brains. J Neurosci 30 , 3489-3498.

Israel, M.A., Yuan, S.H., Bardy, C., Reyna, S.M., Mu, Y., Herrera, C., Hefferan, M.P., Van Gorp, S., Nazor, K.L., Boscolo, F.S., et al. (2012). Probing sporadic and familial Alzheimer's disease using induced pluripotent stem cells. Nature 482, 216-220.

Jessberger, S., Zhao, C., Toni, N., Clemenson, G.D. Jr, Li, Y., and Gage, F.H. (2007). Seizure-associated, aberrant neurogenesis in adult rats characterized with retrovirus-mediated cell labeling. J Neurosci 27, 9400-9407.
Jin, K., Galvan, V., Xie, L., Mao, X.O., Gorostiza, O.F., Bredesen, D.E., and Greenberg, D.A. (2004). Enhanced neurogenesis in Alzheimer's disease transgenic (PDGF-APPSw,Ind) mice. Proc Natl Acad Sci U S A 101, 13363-13367.

Jin, K., Sun, Y., Xie, L., Batteur, S., Mao, X.O., Smelick, C., Logvinova, A., and Greenberg, D.A. (2003). Neurogenesis and aging: FGF-2 and HB-EGF restore neurogenesis in hippocampus and subventricular zone of aged mice. Aging Cell 2, 175-183.

Jin, K., Zhu, Y., Sun, Y., Mao, X.O., Xie, L., and Greenberg, D.A. (2002). Vascular endothelial growth factor (VEGF) stimulates neurogenesis in vitro and in vivo. Proc Natl Acad Sci U S A 99, 11946-11950.

Jones, K.S., and Connor, B. (2011). Proneural transcription factors DIx2 and Pax6 are altered in adult SVZ neural precursor cells following striatal cell loss. Mol Cell Neurosci 47, 53-60.

Kang, E., Burdick, K.E., Kim, J.Y., Duan, X., Guo, J.U., Sailor, K.A., Jung, D.E., Ganesan, S., Choi, S., Pradhan, D., et al. (2011). Interaction between FEZ1 and DISC1 in regulation of neuronal development and risk for schizophrenia. Neuron 72, 559-571.

Kawasaki, H., Mizuseki, K., Nishikawa, S., Kaneko, S., Kuwana, Y., Nakanishi, S., Nishikawa, S.I., and Sasai, Y. (2000). Induction of midbrain dopaminergic neurons from ES cells by stromal cell-derived inducing activity. Neuron 28, 31-40.

Kitayama, T., Yoneyama, M., Tamaki, K., and Yoneda, Y. (2004). Regulation of neuronal differentiation by $\mathrm{N}$-methyl-D-aspartate receptors expressed in neural progenitor cells isolated from adult mouse hippocampus. J Neurosci Res 76, 599-612.

Kohwi, M., Osumi, N., Rubenstein, J.L., and Alvarez-Buylla, A. (2005). Pax6 is required for making specific subpopulations of granule and periglomerular neurons in the olfactory bulb. J Neurosci 25, 6997-7003.

Komitova, M., and Eriksson, P.S. (2004). Sox-2 is expressed by neural progenitors and astroglia in the adult rat brain. Neurosci Lett 369, 24-27.

Kuhn, H.G., Dickinson-Anson, H., and Gage, F.H. (1996). Neurogenesis in the dentate gyrus of the adult rat: age-related decrease of neuronal progenitor proliferation. J Neurosci 16, 2027-2033.

Lee, G., Papapetrou, E.P., Kim, H., Chambers, S.M., Tomishima, M.J., Fasano, C.A., Ganat, Y.M., Menon, J., Shimizu, F., Viale, A., et al. (2009). Modelling pathogenesis and treatment of familial dysautonomia using patient-specific iPSCs. Nature 461, 402-406.

Lee, K.W., Woon, P.S., Teo, Y.Y., and Sim, K. (2012). Genome wide association studies (GWAS) and copy number variation (CNV) studies of the major psychoses: what have we learnt? Neurosci Biobehav Rev 36, 556-571.

Licht, T., Goshen, I., Avital, A., Kreisel, T., Zubedat, S., Eavri, R., Segal, M., Yirmiya, R., and Keshet, E. (2011). Reversible modulations of neuronal plasticity by VEGF. Proc Natl Acad Sci U S A 108, 5081-5086.

Lie, D.C., Colamarino, S.A., Song, H.J., Désiré, L., Mira, H., Consiglio, A., Lein, E.S., Jessberger, S., Lansford, H., Dearie, A.R., et al. (2005). Wnt signalling regulates adult hippocampal neurogenesis. Nature 437, 1370-1375.

Lie, D.C., Dziewczapolski, G., Willhoite, A.R., Kaspar, B.K., Shults, 
C.W., and Gage, F.H. (2002). The adult substantia nigra contains progenitor cells with neurogenic potential. J Neurosci 22, 6639-6649.

Lim, D.A., and Alvarez-Buylla, A. (1999). Interaction between astrocytes and adult subventricular zone precursors stimulates neurogenesis. Proc Natl Acad Sci U S A 96, 7526-7531.

Lim, D.A., Tramontin, A.D., Trevejo, J.M., Herrera, D.G., GarcíaVerdugo, J.M., and Alvarez-Buylla, A. (2000). Noggin antagonizes BMP signaling to create a niche for adult neurogenesis. Neuron 28, 713-726.

Liu, H., and Zhang, S.C. (2011). Specification of neuronal and glial subtypes from human pluripotent stem cells. Cell Mol Life Sci 68 , 3995-4008.

Liu, X., Wang, Q., Haydar, T.F., and Bordey, A. (2005). Nonsynaptic GABA signaling in postnatal subventricular zone controls proliferation of GFAP-expressing progenitors. Nat Neurosci 8, 1179-1187.

Lois, C., and Alvarez-Buylla, A. (1993). Proliferating subventricular zone cells in the adult mammalian forebrain can differentiate into neurons and glia. Proc Natl Acad Sci U S A 90, 2074-2077.

Lois, C., and Alvarez-Buylla, A. (1994). Long-distance neuronal migration in the adult mammalian brain. Science 264, 1145-1148.

López-Toledano, M.A., and Shelanski, M.L. (2007). Increased neurogenesis in young transgenic mice overexpressing human APP(Sw, Ind). J Alzheimers Dis 12, 229-240.

Lorson, C.L., and Androphy, E.J. (1998). The domain encoded by exon 2 of the survival motor neuron protein mediates nucleic acid binding. Hum Mol Genet 7, 1269-1275.

Lorson, C.L., Hahnen, E., Androphy, E.J., and Wirth, B. (1999). A single nucleotide in the SMN gene regulates splicing and is responsible for spinal muscular atrophy. Proc Natl Acad Sci U S A 96, 6307-6311.

Lorson, C.L., Strasswimmer, J., Yao, J.M., Baleja, J.D., Hahnen, E., Wirth, B., Le, T., Burghes, A.H., and Androphy, E.J. (1998). SMN oligomerization defect correlates with spinal muscular atrophy severity. Nat Genet 19, 63-66.

Lucassen, P.J., Stumpel, M.W., Wang, Q., and Aronica, E. (2010). Decreased numbers of progenitor cells but no response to antidepressant drugs in the hippocampus of elderly depressed patients. Neuropharmacology 58, 940-949.

Lugert, S., Basak, O., Knuckles, P., Haussler, U., Fabel, K., Götz, M., Haas, C.A., Kempermann, G., Taylor, V., and Giachino, C. (2010). Quiescent and active hippocampal neural stem cells with distinct morphologies respond selectively to physiological and pathological stimuli and aging. Cell Stem Cell 6, 445-456.

Luskin, M.B. (1993). Restricted proliferation and migration of postnatally generated neurons derived from the forebrain subventricular zone. Neuron 11, 173-189.

Maekawa, M., Takashima, N., Arai, Y., Nomura, T., Inokuchi, K., Yuasa, S., and Osumi, N. (2005). Pax6 is required for production and maintenance of progenitor cells in postnatal hippocampal neurogenesis. Genes Cells 10, 1001-1014.

Marchetto, M.C., Carromeu, C., Acab, A., Yu, D., Yeo, G.W., Mu, Y., Chen, G., Gage, F.H., and Muotri, A.R. (2010a). A model for neural development and treatment of Rett syndrome using human induced pluripotent stem cells. Cell 143, 527-539.

Marchetto, M.C., Winner, B., and Gage, F.H. (2010b). Pluripotent stem cells in neurodegenerative and neurodevelopmental diseases. Hum Mol Genet 19, R71-R76.

[A1]Mejia-Gervacio, S., Murray, K., and Lledo, P.M. (2011). NKCC1 controls GABAergic signaling and neuroblast migration in the postnatal forebrain. Neural Dev 6, 4.

Méndez-Gómez, H.R., Vergaño-Vera, E., Abad, J.L., Bulfone, A., Moratalla, R., de Pablo, F., and Vicario-Abejón, C. (2011). The T-box brain 1 (Tbr1) transcription factor inhibits astrocyte formation in the olfactory bulb and regulates neural stem cell fate. Mol Cell Neurosci 46, 108-121.

Mira, H., Andreu, Z., Suh, H., Lie, D.C., Jessberger, S., Consiglio, A., San Emeterio, J., Hortigüela, R., Marqués-Torrejón, M.A., Nakashima, K., et al. (2010). Signaling through BMPR-IA regulates quiescence and long-term activity of neural stem cells in the adult hippocampus. Cell Stem Cell 7, 78-89.

Morshead, C.M., Reynolds, B.A., Craig, C.G., McBurney, M.W., Staines, W.A., Morassutti, D., Weiss, S., and van der Kooy, D. (1994). Neural stem cells in the adult mammalian forebrain: a relatively quiescent subpopulation of subependymal cells. Neuron 13, 1071-1082.

Mu, Y., Lee, S.W., and Gage, F.H. (2010). Signaling in adult neurogenesis. Curr Opin Neurobiol 20, 416-423.

Muroyama, Y., Kondoh, H., and Takada, S. (2004). Wnt proteins promote neuronal differentiation in neural stem cell culture. Biochem Biophys Res Commun 313, 915-921.

Muth-Köhne, E., Terhag, J., Pahl, S., Werner, M., Joshi, I., and Hollmann, M. (2010). Functional excitatory GABAA receptors precede ionotropic glutamate receptors in radial glia-like neural stem cells. Mol Cell Neurosci 43, 209-221.

Nacher, J., Varea, E., Blasco-Ibañez, J.M., Castillo-Gomez, E., Crespo, C., Martinez-Guijarro, F.J., and McEwen, B.S. (2005). Expression of the transcription factor Pax 6 in the adult rat dentate gyrus. J Neurosci Res 81, 753-761.

Nácher, J., Varea, E., Miguel Blasco-lbáñez, J., Gómez-Climent, M.A., Castillo-Gómez, E., Crespo, C., Martínez-Guijarro, F.J., and McEwen, B.S. (2007). N-methyl-d-aspartate receptor expression during adult neurogenesis in the rat dentate gyrus. Neuroscience 144, 855-864.

O'Donovan, M.C., Craddock, N., Norton, N., Williams, H., Peirce, T., Moskvina, V., Nikolov, I., Hamshere, M., Carroll, L., Georgieva, L., et al., and the Molecular Genetics of Schizophrenia Collaboration. (2008). Identification of loci associated with schizophrenia by genome-wide association and follow-up. Nat Genet 40, 1053-1055.

O'Keeffe, G.C., Barker, R.A., and Caldwell, M.A. (2009). Dopaminergic modulation of neurogenesis in the subventricular zone of the adult brain. Cell Cycle 8, 2888-2894.

Pan, B., Huang, X.F., and Deng, C. (2011). Antipsychotic treatment and neuregulin 1-ErbB4 signalling in schizophrenia. Prog Neuropsychopharmacol Biol Psychiatry 35, 924-930.

Parent, J.M., Jessberger, S., Gage, F.H., and Gong, C. (2007). Is neurogenesis reparative after status epilepticus? Epilepsia 48, 69-71. 
Park, I.H., Arora, N., Huo, H., Maherali, N., Ahfeldt, T., Shimamura, A., Lensch, M.W., Cowan, C., Hochedlinger, K., and Daley, G.Q. (2008). Disease-specific induced pluripotent stem cells. Cell 134, 877-886.

Pedrosa, E., Sandler, V., Shah, A., Carroll, R., Chang, C., Rockowitz, S., Guo, X., Zheng, D., and Lachman, H.M. (2011). Development of patient-specific neurons in schizophrenia using induced pluripotent stem cells. J Neurogenet 25, 88-103.

Peretto, P., Giachino, C., Aimar, P., Fasolo, A., and Bonfanti, L. (2005). Chain formation and glial tube assembly in the shift from neonatal to adult subventricular zone of the rodent forebrain. $J$ Comp Neurol 487, 407-427.

Peretto, P., Merighi, A., Fasolo, A., and Bonfanti, L. (1997). Glial tubes in the rostral migratory stream of the adult rat. Brain Res Bull 42, 9-21.

Peretto, P., Merighi, A., Fasolo, A., and Bonfanti, L. (1999). The subependymal layer in rodents: a site of structural plasticity and cell migration in the adult mammalian brain. Brain Res Bull 49, 221-243.

Pierfelice, T., Alberi, L., and Gaiano, N. (2011). Notch in the vertebrate nervous system: an old dog with new tricks. Neuron 69, 840-855.

Ponti, G., Aimar, P., and Bonfanti, L. (2006). Cellular composition and cytoarchitecture of the rabbit subventricular zone and its extensions in the forebrain. J Comp Neurol 498, 491-507.

Ramírez-Castillejo, C., Sánchez-Sánchez, F., Andreu-Agulló, C., Ferrón, S.R., Aroca-Aguilar, J.D., Sánchez, P., Mira, H., Escribano, J., and Fariñas, I. (2006). Pigment epithelium-derived factor is a niche signal for neural stem cell renewal. Nat Neurosci 9 , 331-339.

Reynolds, B.A., and Weiss, S. (1992). Generation of neurons and astrocytes from isolated cells of the adult mammalian central nervous system. Science 255, 1707-1710.

Rietze, R., Poulin, P., and Weiss, S. (2000). Mitotically active cells that generate neurons and astrocytes are present in multiple regions of the adult mouse hippocampus. J Comp Neurol 424, 397-408.

Ripke, S., Sanders, A.R., Kendler, K.S., Levinson, D.F., Sklar, P., Holmans, P.A., Lin, D.Y., Duan, J., Ophoff, R.A., Andreassen, O.A., et al., and the Schizophrenia Psychiatric Genome-Wide Association Study (GWAS) Consortium. (2011). Genome-wide association study identifies five new schizophrenia loci. Nat Genet 43, 969-976.

Rodríguez, J.J., Jones, V.C., Tabuchi, M., Allan, S.M., Knight, E.M., LaFerla, F.M., Oddo, S., and Verkhratsky, A. (2008). Impaired adult neurogenesis in the dentate gyrus of a triple transgenic mouse model of Alzheimer's disease. PLoS One 3, e2935.

Roy, N.S., Cleren, C., Singh, S.K., Yang, L., Beal, M.F., and Goldman, S.A. (2006). Functional engraftment of human ES cell-derived dopaminergic neurons enriched by coculture with telomeraseimmortalized midbrain astrocytes. Nat Med 12, 1259-1268.

Roybon, L., Hjalt, T., Stott, S., Guillemot, F., Li, J.Y., and Brundin, P. (2009). Neurogenin2 directs granule neuroblast production and amplification while NeuroD1 specifies neuronal fate during hip- pocampal neurogenesis. PLoS One 4, e4779.

Samaco, R.C., Hogart, A., and LaSalle, J.M. (2005). Epigenetic overlap in autism-spectrum neurodevelopmental disorders: MECP2 deficiency causes reduced expression of UBE3A and GABRB3. Hum Mol Genet 14, 483-492.

Schneider, B.L., Seehus, C.R., Capowski, E.E., Aebischer, P., Zhang, S.C., and Svendsen, C.N. (2007). Over-expression of alphasynuclein in human neural progenitors leads to specific changes in fate and differentiation. Hum Mol Genet 16, 651-666.

Schulz-Schaeffer, W.J. (2010). The synaptic pathology of alphasynuclein aggregation in dementia with Lewy bodies, Parkinson's disease and Parkinson's disease dementia. Acta Neuropathol 120, 131-143.

Segawa, M. (2001). Pathophysiology of Rett syndrome from the stand point of clinical characteristics. Brain Dev 23, S94-S98.

Seki, T., and Arai, Y. (1993). Highly polysialylated neural cell adhesion molecule (NCAM-H) is expressed by newly generated granule cells in the dentate gyrus of the adult rat. J Neurosci 13, 2351-2358.

Selkoe, D.J. (2001). Alzheimer's disease: genes, proteins, and therapy. Physiol Rev 81, 741-766.

Singh, K.K., De Rienzo, G., Drane, L., Mao, Y., Flood, Z., Madison, J., Ferreira, M., Bergen, S., King, C., Sklar, P., et al. (2011). Common DISC1 polymorphisms disrupt Wnt/GSK3 signaling and brain development. Neuron 72, 545-558.

Slaugenhaupt, S.A., Blumenfeld, A., Gill, S.P., Leyne, M., Mull, J., Cuajungco, M.P., Liebert, C.B., Chadwick, B., Idelson, M., Reznik, L., et al. (2001). Tissue-specific expression of a splicing mutation in the IKBKAP gene causes familial dysautonomia. Am J Hum Genet 68, 598-605.

[A2][A3]Soares, D.C., Carlyle, B.C., Bradshaw, N.J., and Porteous, D.J. (2011). DISC1: Structure, Function, and Therapeutic Potential for Major Mental Illness. ACS Chem Neurosci 2, 609-632.

Soldner, F., Hockemeyer, D., Beard, C., Gao, Q., Bell, G.W., Cook, E.G., Hargus, G., Blak, A., Cooper, O., Mitalipova, M., et al. (2009). Parkinson's disease patient-derived induced pluripotent stem cells free of viral reprogramming factors. Cell 136, 964-977.

Song, H., Stevens, C.F., and Gage, F.H. (2002a). Astroglia induce neurogenesis from adult neural stem cells. Nature 417, 39-44.

Song, H.J., Stevens, C.F., and Gage, F.H. (2002b). Neural stem cells from adult hippocampus develop essential properties of functional CNS neurons. Nat Neurosci 5, 438-445.

Spitere, K., Toulouse, A., O'Sullivan, D.B., and Sullivan, A.M. (2008). TAT-PAX6 protein transduction in neural progenitor cells: a novel approach for generation of dopaminergic neurones in vitro. Brain Res 1208, 25-34.

Stefansson, H., Ophoff, R.A., Steinberg, S., Andreassen, O.A., Cichon, S., Rujescu, D., Werge, T., Pietiläinen, O.P., Mors, O., Mortensen, P.B., et al., and the Genetic Risk and Outcome in Psychosis (GROUP). (2009). Common variants conferring risk of schizophrenia. Nature 460, 744-747.

Suh, H., Consiglio, A., Ray, J., Sawai, T., D'Amour, K.A., and Gage, F.H. (2007). In vivo fate analysis reveals the multipotent and self-renewal capacities of Sox $2+$ neural stem cells in the adult 
hippocampus. Cell Stem Cell 1, 515-528.

Suh, H., Deng, W., and Gage, F.H. (2009). Signaling in adult neurogenesis. Annu Rev Cell Dev Biol 25, 253-275.

Takahashi, K., Tanabe, K., Ohnuki, M., Narita, M., Ichisaka, T., Tomoda, K., and Yamanaka, S. (2007). Induction of pluripotent stem cells from adult human fibroblasts by defined factors. Cell 131, 861-872.

Taranova, O.V., Magness, S.T., Fagan, B.M., Wu, Y., Surzenko, N., Hutton, S.R., and Pevny, L.H. (2006). SOX2 is a dose-dependent regulator of retinal neural progenitor competence. Genes Dev 20, 1187-1202.

Tattersfield, A.S., Croon, R.J., Liu, Y.W., Kells, A.P., Faull, R.L., and Connor, B. (2004). Neurogenesis in the striatum of the quinolinic acid lesion model of Huntington's disease. Neuroscience 127, 319-332.

Toni, N., Teng, E.M., Bushong, E.A., Aimone, J.B., Zhao, C., Consiglio, A., van Praag, H., Martone, M.E., Ellisman, M.H., and Gage, F.H. (2007). Synapse formation on neurons born in the adult hippocampus. Nat Neurosci 10, 727-734.

Tozuka, Y., Fukuda, S., Namba, T., Seki, T., and Hisatsune, T. (2005). GABAergic excitation promotes neuronal differentiation in adult hippocampal progenitor cells. Neuron 47, 803-815.

van Praag, H., Schinder, A.F., Christie, B.R., Toni, N., Palmer, T.D., and Gage, F.H. (2002). Functional neurogenesis in the adult hippocampus. Nature 415, 1030-1034.

Vekrellis, K., Xilouri, M., Emmanouilidou, E., Rideout, H.J., and Stefanis, L. (2011). Pathological roles of -synuclein in neurological disorders. Lancet Neurol 10, 1015-1025.

Verret, L., Jankowsky, J.L., Xu, G.M., Borchelt, D.R., and Rampon, C. (2007). Alzheimer's-type amyloidosis in transgenic mice impairs survival of newborn neurons derived from adult hippocampal neurogenesis. J Neurosci 27, 6771-6780.

Walter, C., Murphy, B.L., Pun, R.Y., Spieles-Engemann, A.L., and Danzer, S.C. (2007). Pilocarpine-induced seizures cause selective time-dependent changes to adult-generated hippocampal dentate granule cells. J Neurosci 27, 7541-7552.

Wegner, F., Kraft, R., Busse, K., Schaarschmidt, G., Härtig, W., Schwarz, S.C., and Schwarz, J. (2009). Glutamate receptor properties of human mesencephalic neural progenitor cells: NMDA enhances dopaminergic neurogenesis in vitro. J Neurochem 111, 204-216.

Wen, P.H., Hof, P.R., Chen, X., Gluck, K., Austin, G., Younkin, S.G., Younkin, L.H., DeGasperi, R., Gama Sosa, M.A., Robakis, N.K., et al. (2004). The presenilin-1 familial Alzheimer disease mutant
P117L impairs neurogenesis in the hippocampus of adult mice. Exp Neurol 188, 224-237.

Werning, M., Zhao, J.P., Pruszak, J., Hedlund, E., Fu, D., Soldner, F., Broccoli, V., Constantine-Paton, M., Isacson, O., and Jaenisch, R. (2008). Neurons derived from reprogrammed fibroblasts functionally integrate into the fetal brain and improve symptoms of rats with Parkinson's disease. Proc Natl Acad Sci USA 105, 5856-5861.

Winner, B., Kohl, Z., and Gage, F.H. (2011). Neurodegenerative disease and adult neurogenesis. Eur J Neurosci 33, 1139-1151.

Yamashita, H., Nakamura, T., Takahashi, T., Nagano, Y., Hiji, M., Hirabayashi, T., Amano, T., Yagi, T., Sakai, N., Kohriyama, T., et al. (2006). Embryonic stem cell-derived neuron models of Parkinson's disease exhibit delayed neuronal death. J Neurochem 98, 45-56.

Yokley, J.L., Prasad, K.M., Chowdari, K.V., Talkowski, M.E., Wood, J., Gur, R.C., Gur, R.E., Almasy, L., Nimgaonkar, V.L., and Pogue-Geile, M.F. (2011). Genetic associations between neuregulin-1 SNPs and neurocognitive function in multigenerational, multiplex schizophrenia families. Psychiatr Genet. 2011 Dec 16. [Epub ahead of print]

Yoneyama, M., Nakamichi, N., Fukui, M., Kitayama, T., Georgiev, D.D., Makanga, J.O., Nakamura, N., Taniura, H., and Yoneda, Y. (2008). Promotion of neuronal differentiation through activation of $\mathrm{N}$-methyl-D-aspartate receptors transiently expressed by undifferentiated neural progenitor cells in fetal rat neocortex. J Neurosci Res 86, 2392-2402.

Yoshinaga, Y., Kagawa, T., Shimizu, T., Inoue, T., Takada, S., Kuratsu, J., and Taga, T. (2010). Wnt3a promotes hippocampal neurogenesis by shortening cell cycle duration of neural progenitor cells. Cell Mol Neurobiol 30, 1049-1058.

Yu, J., Vodyanik, M.A., Smuga-Otto, K., Antosiewicz-Bourget, J., Frane, J.L., Tian, S., Nie, J., Jonsdottir, G.A., Ruotti, V., Stewart, $\mathrm{R}$., et al. (2007). Induced pluripotent stem cell lines derived from human somatic cells. Science 318, 1917-1920.

[A4]Yuan, L., Zhou, X., Li, D., Ma, W., Yu, H., Xi, Y., and Xiao, R. (2012). Pattern recognition receptors involved in the inflammatory attenuating effects of soybean isoflavone in -amyloid peptides 1-42 treated rats. Neurosci Lett 506, 266-270.

Zhang, C., McNeil, E., Dressler, L., and Siman, R. (2007). Longlasting impairment in hippocampal neurogenesis associated with amyloid deposition in a knock-in mouse model of familial Alzheimer's disease. Exp Neurol 204, 77-87.

Zhao, C., Deng, W., and Gage, F.H. (2008). Mechanisms and functional implications of adult neurogenesis. Cell 132, 645-660. 